\title{
What Is HR Management? - Based on the Matching of People and Posts
}

\author{
Xiao Li \\ School of Management, Jinan University, Guangzhou, China \\ Email:2311577856@qq.com
}

How to cite this paper: Li, X. (2018) What Is HR Management?-Based on the Matching of People and Posts. Journal of Human Resource and Sustainability Studies, 6, 215-227.

https://doi.org/10.4236/jhrss.2018.63038

Received: June 15, 2018

Accepted: September 3, 2018

Published: September 6, 2018

Copyright $\odot 2018$ by author and Scientific Research Publishing Inc. This work is licensed under the Creative Commons Attribution International License (CC BY 4.0).

http://creativecommons.org/licenses/by/4.0/

\begin{abstract}
In the final analysis, the competition among enterprises in the 21 st century is the competition of human resources. Human resources management is still a great challenge for enterprises, and talent recruitment, brain drain and other issues are endless. In response to this problem, the article uses GATCO (Guangzhou) as an example to analyze the connotation and relationship of the components of human resource management based on the matching of people and posts. Research shows that, firstly, human resources management consists of four factors: human post matching, people matching, post matching, compensationand performance matching. Among them, post matching is the basis, performance compensation matching is the tool, and post matching is the strategic goal. Being oriented, everyone matching is the essence of achieving the strategic goal of post; Secondly, the ultimate orientation of human resource management activity is the realization of employee self-value and the realization of corporate value. Among them, the realization of employee value is the premise of the realization of enterprise value; Thirdly, the most critical part of the post matching is talent, not post; Fourthly, the operation of human resources management activities comes from the joint forces among various elements. Its essence is a series of activities carried out under the guidance of strategic goals, based on positions, and human-centered.
\end{abstract}

\section{Keywords}

Human Resources, Human Resources Management, People Post Matching, Post Matching, People Match, Compensation Performance Matching

\section{Introduction}

With the development of economic globalization and the intensification of competition, effective human resources management has become the key to the 
survival and development of enterprises. The management staff from the posts is deeply ingrained in that management is a process of decision making, planning, organization, execution, and control, and aims to improve efficiency and effectiveness. Regarding human resources management, it is generally acknowledged that there are six major sections: human resources planning, recruitment and deployment, training and development, performance management, compensation and benefits management, and employee relationship management. Practice has proved that the efficiency of human resources management under this concept is not high. In recent years, the National Bureau of Statistics shows that there were 6.59 million regular undergraduates and specialist graduates in 2014, 7.49 million in 2015, and 7.65 million in 2016 [1]. For graduates, graduation means unemployment; companies face such a huge amount. The college graduates' employment group has been troubled all day long to find no suitable talents. In addition, the internal staff of the company is seriously drained. Taking the Guangzhou region as an example, in the third quarter of 2014, the Guangdong Office of Human Resources and Social Security conducted a spot-sampling survey of 350 enterprises in the Pearl River Delta region. According to the survey results, the personnel turnover rate of lighting manufacturing companies was $43.85 \%$, that of household appliances was $30.2 \%$, that of paper products was $51.3 \%$, and that of catering industry was even as high as $55.2 \%$ [2]. It can be seen that the six major sections of human resource management do not reflect the true meaning of human resource management. Enterprises still face the challenge of human resource management. So, what is the essence and meaning of human resource management?

In order to answer this question, domestic scholars have carried out a large amount of research based on human resource management. According to the research level and dimension, they are divided into macroscopic and microscopic aspects. The macro level focuses on the impact of human resources management on the organization, such as organizational performance, core competitiveness, etc.; micro level focuses on training and development, recruitment and selection, salary design labor relations, psychological contract, satisfaction, loss rate and so on. Although these studies provide a solid theoretical basis for human resource management practices, they do not provide an in-depth analysis of the nature of human resource management. For this reason, this paper analyzes GATCO (Guangzhou) based on the matching of people and post, and analyzes the internal composition and connotation of human resource management and the logical relationship between components, in order to provide theoretical guidance for human resource management practice.

\section{Literature Review}

\subsection{Research Status}

Throughout the research of Chinese scholars on the matching of human post, the research topics focus on the four aspects of human post dynamic matching, job matching system, human post matching construction and human and or- 
ganization matching.

Post matching dynamicly

The research on the dynamic matching of human posts focuses on the process and model of dynamic matching of human posts. In terms of the dynamic matching process of the post, Tang is the representative. He compiled a dynamic flow chart of Chinese enterprises based on competency perspectives, and proposed a dynamic flow chart that matches the current diagnosis and the matching degree of employees. The first evaluation, adjustment according to the status of the company's competency, and the degree of matching of the company's employees were evaluated again in four steps [3]. In the dynamic matching model of the post, Luo Weiliang put forward three types of relationships, mobile configuration model, and mobile configuration model [4]. Among them, the post configuration model aims to ensure the quality of human resources and is a bidirectional choice of configuration; the mobile match-type manifestations include promotion, demotion, and redeployment; and the mobility configuration is reflected in the three aspects of resettlement, adjustment, and dismissal.

Post Matching System

The job matching system theory was put forward by Huang Huanshan and Liu Fan. They think that post matching is a system. There are subsystems such as job and quality matching, job and compensation matching, job and management matching, job and price matching, and job and space matching subsystems. The composition makes the "distribution according to work" a new look [5]. In addition, from the perspective of job design, Wang Liping believes that post matching in job design is divided into post matching, post matching, person matching, and post and compensation matching [6]. Although Wang Liping's content is not as rich as Huang Huanshan's, it shows the key content of the match between man and post.

Post matching construction

Regarding the post matching construction, the representative author is $\mathrm{Xu}$ Rongrong. She proposed the matching elements, forms, principles, and post matching construction steps [7]. In the post matching and construction steps, $\mathrm{Xu}$ Rongrong pointed out that knowing posts the starting point and cornerstone of the matching of people, including the work itself and the qualifications of the incumbent; knowledge is the key link for matching people; Putting the right person in the right place is the optimization of the post last step.

People and organizations match

The research perspective of human-organization matching focuses on the consistency between the intrinsic characteristics of the human body and the basic characteristics of the organization. Jin Yanghua and others collated Kristof's matching model of humans and organizations, and analyzed direct and indirect measurements of human-tissue matching. The relationship is between people and organization match and other variables such as turnover behavior, organizational commitment, task performance, etc. [8]. 


\subsection{Literature Review}

Through combing the research on the post matching of people, we know the focus of the research on the matchmaking of the post, and clear the current research status of the scholars on post matching, which provides a good theoretical basis for this paper. Looking at the research of former scholars, although it is becoming increasingly sophisticated, it still has the following deficiencies: Firstly, in the aspect of dynamic matching of posts, the dynamic matching process for posts is focused on evaluation. The assessment criteria will change due to changes in the actual situation of the company. The nature of the post matching model is the change in the distribution of personnel from recruitment to departure. It does not essentially analyze the dynamic model of post. Secondly, post-matching system theory, which is rich in content and clear, neglects to analyze the relationship between subsystems and the interaction between each other, and overemphasizes the content of subsystems. Thirdly, in the aspect of human post matching and construction, the combing of construction steps is too simple, and the detailed implementation details of each step need to be further clarified; Fourthly, most of the research methods are based on qualitative research to discuss the corresponding measures and steps, and lack of case supplements. Therefore, this article will use the grounded theory to sort out the essential connotation of a company's human resource management, discuss its components of human resource management, analyze the connotation and logical relationship of each component, and provide reference for the human resource management in the industry.

\section{Research Methods}

\subsection{Research Design}

\section{1) Grounded Theory}

The grounded theory is a method of constructing theories based on empirical materials. Through in-depth analysis of the original data, the theory is gradually summarized. The core is the process of data collection and analysis. The process includes both theoretical deduction and theoretical induction [9]. In addition, data collection and analysis are simultaneous, simultaneous, and continuous cycles [10]. This study mainly adopts the method of procedural grounded theory, and encodes the text data of case companies according to the order of open coding, spindle coding and selective coding, and finally forms the core content of human resource management and the deconstruction of its internal relations.

\section{2) Interviews}

Through interviews, research subjects can be induced to describe, interpret, and reflect in a way that rarely occurs in everyday life, so that a specific problem can be studied in depth. In the actual interviews, recording materials such as recording pens and notebooks were prepared in advance. Semi-structured or in- 
formal interviews were conducted. Questions were asked according to the case study design. The questions were kept neutral to obtain the required information.

\subsection{Brief Introduction of GATCO}

GATCO (Guangzhou) Automatic Transmission Co., Ltd. (hereinafter referred to as GATCO Guangzhou) is a branch of Nissan Motor Co., Ltd.'s JATCO Co., Ltd., which was founded in April 2007 and officially put into operation in September 2009. In 2017, we celebrated our 10th anniversary. GATCO (Guangzhou), as the leader in the domestic transmission manufacturer, mainly produces stepless automatic transmissions. Since its establishment, its production capacity has increased from the initial 144,000 units/year to the current 1.2 million units/year, achieving a leap-forward development. The number of employees has also increased from 250 to more than 2000. It has become an important production base for Gutco's transnational operations. The improvement of production cannot be separated from talents. The management of talents cannot be separated from human resources. GATCO (Guangzhou) regards people's wealth as a special noun, which emphasizes the use of human resources as a kind of value-creating wealth. It is a key element of the company. It has developed a series of human resources planning system around people's wealth. The financial training system and the human resources promotion system have created splendid honors and corporate values, and have been well received by the industry.

\section{Data Collection and Processing}

\subsection{Data Collection}

The data collection of this paper mainly includes two methods: literature research and interview. The reason why we use two methods to collect information is because the information obtained by the two methods can complement and verify each other. Through open interviews to obtain future data, data analysis to form the concept and scope, supplemented by secondary literature and company internal propaganda materials, to compare the concepts and categories of primary data formation coding, in order to verify and supplement the theoretical saturation. In terms of interview materials, the team formed an interview and research team together with students to visit GATCO (Guangzhou) and conduct interviews with GATCO employees. The interviewees ranged from the general staff of the Human Resources Department to Mr. Huang, the minister and deputy general manager of the company. After the interview, the collected audio recordings are named after the "IX-time object", where "I" represents the interview data and $\mathrm{X}$ represents the interview code. The specific interview arrangements are shown in Table 1, and the interview data are shown in Table 2. For second-hand materials, the company conducted code analysis through public information materials such as GATCO (Guangzhou) internal periodicals, and on the other hand, it was retrieved from China Knowledge Network. 
Table 1. Interview.

\begin{tabular}{|c|c|c|c|c|c|}
\hline Interview time & coding & Interview group & Interviewee & Interviewee position & location \\
\hline \multirow{3}{*}{$2017 / 8 / 20$} & I1-20170820 & Li Xiao/Zhou Yiting & Mr. Huang & Deputy General Manager & Company reception hall \\
\hline & I2-20170820 & Li Xiao/Zhou Yiting & Mr. Liu & Human Resources Minister & Company reception hall \\
\hline & I3-20170820 & Li Xiao/Zhou Yiting & Miss $\mathrm{He}$ & HR staff & Company reception hall \\
\hline $2017 / 10 / 12$ & I4-20171012 & Li Xiao/Chen Xin & Miss Wei & Human Resources Minister & Minister's Office \\
\hline \multirow{2}{*}{$2018 / 3 / 18$} & I5-20180318 & Li Xiao/Chen Xin & Employee A & HR staff & Company meeting room \\
\hline & I6-20180318 & Li Xiao/Chen Xin & Employee B & HR staff & Company meeting room \\
\hline
\end{tabular}

Attached: This is derived from the author.

Table 2. Interview data.

\begin{tabular}{|c|c|c|}
\hline \multirow[t]{2}{*}{ Mr. Huang } & $\begin{array}{l}\text { Analyze } 5 \text { people to become } 8 \text { people, then how the work fits in, empty all play well, analyze it, } \\
\text { next is the inventory of our people, I have four characteristics of the four of us to check } \\
\text { what are the characteristics, what do you do next? You will bring someone next year. } \\
\text { If you bring someone, you will be able to do it separately. }\end{array}$ & Talent analysis \\
\hline & $\begin{array}{l}\text { Now that the second factory has come, we need to remove some people here. } \\
\text { So this year's task is very heavy, because people here have to take it away, } \\
\text { but also need to fill in some people and need to train a group of back-up talents. }\end{array}$ & $\begin{array}{l}\text { Alternate } \\
\text { personnel } \\
\text { training }\end{array}$ \\
\hline Miss $\mathrm{He}$ & $\begin{array}{l}\text { We started the construction of the factory again, and we used Japanese and English } \\
\text { for the recruitment. Language is the most basic requirement. Foreign language is the } \\
\text { basic requirement. The content of the job is to be in Japanese, and that job requires Japanese. }\end{array}$ & $\begin{array}{l}\text { Job } \\
\text { requirements }\end{array}$ \\
\hline Mr. Liu & $\begin{array}{l}\text { What we need to do is to communicate with each other more often and understand each } \\
\text { other's personalities. If we are to arrange work in the future, we will have targeted arrangements. }\end{array}$ & $\begin{array}{l}\text { Knowing people } \\
\text { and make } \\
\text { use of them }\end{array}$ \\
\hline Miss Wei & $\begin{array}{l}\text { There are also many activities in peacetime. There are New Year's vows and red envelopes. These are } \\
\text { not found in Japan. Unions will also send red envelopes. New products will be released. It will be a } \\
\text { big event. It will celebrate with employees, send some bonuses, and forget about annual meetings. }\end{array}$ & $\begin{array}{l}\text { Employee } \\
\text { benefits }\end{array}$ \\
\hline Employee A & $\begin{array}{l}\text { One means to increase production capacity is to increase OEE (Comprehensive Equipment Efficiency). } \\
\text { There are many issues in this design. We will combine the technologies, the preservation site, } \\
\text { the inspection, the production management, and other departments to improve together to } \\
\text { achieve higher production capacity. The way of cooperation has been used very much. }\end{array}$ & $\begin{array}{l}\text { Cross-sector } \\
\text { cooperation }\end{array}$ \\
\hline Employee B & $\begin{array}{l}\text { Good intra-departmental collaboration is also a further warming of team feelings. Every year, when faith, } \\
\text { Christmas and other festivals send small gifts to each other, electronic albums and birthday cards } \\
\text { elaborately prepared by members on their birthdays, the thoughtfulness and visit of female employees } \\
\text { during pregnancy, private sharing during the monthly regular meetings, all members feel the home warm. }\end{array}$ & Employee care \\
\hline
\end{tabular}

Attached: This is derived from the author.

\subsection{Data Processing}

\section{1) Data tagging}

Tagging refers to the process of collecting the first-hand data and the second-hand information from the interview process, reading it word by word, recording the content related to the topic, and labeling it, summarizing the relatively lengthy paragraphs or sentences, and then tagging them. In the tagging process, the fact-based principle is followed, and the data is tagged objectively and stored in the form of "IX-ax" and "TX-ax", where "I" represents the inter- 
view data, " $\mathrm{T}$ " represents the second-hand data, and "ax" represents the tag number.

\section{2) Data conceptualization}

Conceptualization of data is the process of refining and integrating tagged sentences and paragraphs into concepts. Conceptualization can be directly extracted from the data summary, and can also be generalized. The premise is to ensure that the extracted concepts can reflect the nature of the data. The concept is named "aax". For example, aal indicates the first concept extracted from the label summary.

\section{3) Data categorization}

The categorization of data materials is the process of integrating related concepts or concepts of the same type formed in the conceptualization process to form a generic process, which is also called genericization. The category that the concept is categorized into is called the subcategory and is a deeper refinement of the concept. This article names the subcategories in the form of "AX". For example, "Al" represents the first subcategory that is integrated from the concept.

By tagging, conceptualizing, and categorizing the data, sentences and fragments of the same meaning were deleted. A total of 78 interview tags and 54 literature tags were obtained, and 47 concepts and 15 subcategories were extracted and summarized, which can be seen in Table 3 and Table 4 .

\section{4) Spindle coding}

Spindle coding aims to better develop the main categories, further enrich the

Table 3. Example of encoding stage.

\begin{tabular}{|c|c|c|c|c|}
\hline Case practice analysis fragment & Tagging & $\begin{array}{l}\text { Concise } \\
\text { information }\end{array}$ & conceptualization & Generic \\
\hline $\begin{array}{l}\text { In terms of personnel training, this piece of skills is } \\
\text { particularly fine and very good, as well as rewards. There } \\
\text { is not much difference with the tutorial system. } \\
\text { A tutor takes several people. }\end{array}$ & I1-a1 & & $\begin{array}{l}\text { Aa1 Teacher Training } \\
\text { with Discipline Talents }\end{array}$ & A1 talent Education \\
\hline $\begin{array}{l}\text { When the company plans to do five-year planning, } \\
\text { we now need to inventory, we first do a five-year plan, } \\
\text { this year is how, next year is how. }\end{array}$ & I1-a2 & $\begin{array}{l}\text { Talent Planning } \\
\text { Based on } \\
\text { Corporate Planning }\end{array}$ & $\begin{array}{l}\text { Aa2 Corporate } \\
\text { talent planning }\end{array}$ & A2 Talent planning \\
\hline $\begin{array}{l}\text { What are the advantages and disadvantages } \\
\text { of the candidate? All are listed and what } \\
\text { are the shortcomings. }\end{array}$ & I1-a3 & $\begin{array}{l}\text { An analysis of the } \\
\text { candidate's strengths } \\
\text { and weaknesses }\end{array}$ & $\begin{array}{l}\text { Aa3 Analyze the } \\
\text { advantages and } \\
\text { disadvantages of talents }\end{array}$ & A3 Talent analysis \\
\hline $\begin{array}{l}\text { We are now divided into four types of talents, global } \\
\text { talents (can be in the United States, France, etc.), } \\
\text { local talents, international talents, and local talents. }\end{array}$ & $\mathrm{I} 1-\mathrm{a} 4$ & & $\begin{array}{l}\text { Aa4 Company Talent } \\
\text { Classification Analysis }\end{array}$ & A3 Talent analysis \\
\hline $\begin{array}{l}\text { In terms of competency, performance has an } \\
\text { evaluation. After the evaluation, the education } \\
\text { department targeted the development of the curriculum. }\end{array}$ & $\mathrm{I} 1-\mathrm{a} 5$ & & $\begin{array}{l}\text { Aa5 Competency } \\
\text { evaluation }\end{array}$ & $\begin{array}{l}\text { A4 Performance } \\
\text { Evaluation System }\end{array}$ \\
\hline $\begin{array}{l}\text { What is the purpose of the rotation, my plan, and why } \\
\text { is it his turn, and what will happen after } 1978 \text { ? He wants } \\
\text { to improve his ability in this area. I must consider it. }\end{array}$ & I1-a6 & & Aa6 Rotation & A1 Talent Education \\
\hline
\end{tabular}

Attached: This is derived from the author. 
Table 4. Coding subcategories.

\begin{tabular}{|c|c|c|c|c|c|}
\hline A1 & Talent Education & A6 & Job Requirements & A11 & Self-realization \\
\hline A2 & Talent Planning & A7 & $\begin{array}{l}\text { Compensation } \\
\text { and Benefit System }\end{array}$ & $\mathrm{A} 12$ & Economic Value \\
\hline A3 & Talent Analysis & A8 & Job Promotion System & $\mathrm{A} 13$ & Social Value \\
\hline A4 & $\begin{array}{c}\text { Performance } \\
\text { Evaluation System }\end{array}$ & A9 & Business Matching & $\mathrm{A} 14$ & Team Building \\
\hline A5 & Communication Mechanism & A10 & Information System & A15 & Strategic Needs \\
\hline
\end{tabular}

Attached: This is derived from the author.

concepts and connotations of the categories, make the categories more rigorous, and benefit from clarifying the relationship between categories. Following the deep meaning expressed by raw materials, combined with the previous research on the matching of post by the scholars, the four main categories of matching of posts, matching of people, matching posts, and matching of rewards and performance were finally formed, as detailed in Table 5 .

When the coding of the main axis is completed, some "story lines" appear back and forth, and the "story lines" are mainly used to determine and strengthen the relationship between categories and categories. This process can be accomplished through a model of "conditions-actions/strategies-results", which concatenates the connotations of human resource management activities.

After in-depth analysis of the content of the category, the following story lines are combed out: employees take self-realization as the ultimate orientation, and companies conduct business activities based on economic and social values. At the same time, the two are not in contradiction. The realization of the enterprise value is achieved through the realization of employee value implemented. To achieve self-fulfillment, employees need clear job requirements.

The basic quality and ability of the company depend on the enterprise to carry out talent analysis, based on talent analysis and job requirements, and implement talent training so as to achieve matchmaking. The performance evaluation is used to verify the matching effect of the post, supplemented by the remuneration and benefits and the position promotion system to motivate the employees to form a performance-based compensation match. The job setup needs to be guided by the company's strategic needs. In the information transfer, the business matching set for realizing the strategic needs is implemented so as to achieve post matching. The essence of Ganggang Matching is team building. Team building is based on knowledge, personnel, and personnel collocation. Under the guidance of the communication mechanism, teams are formed to achieve a match for everyone. After the implementation of job matching, performance-based compensation matching, job matching, and match-making, employees achieve self-worth while achieving economic and social value.

This study will organize the logical structure between the main categories as shown in Figure 1. Through the comparative analysis of research topics and existing literature, the connotation of human resources management is finally 


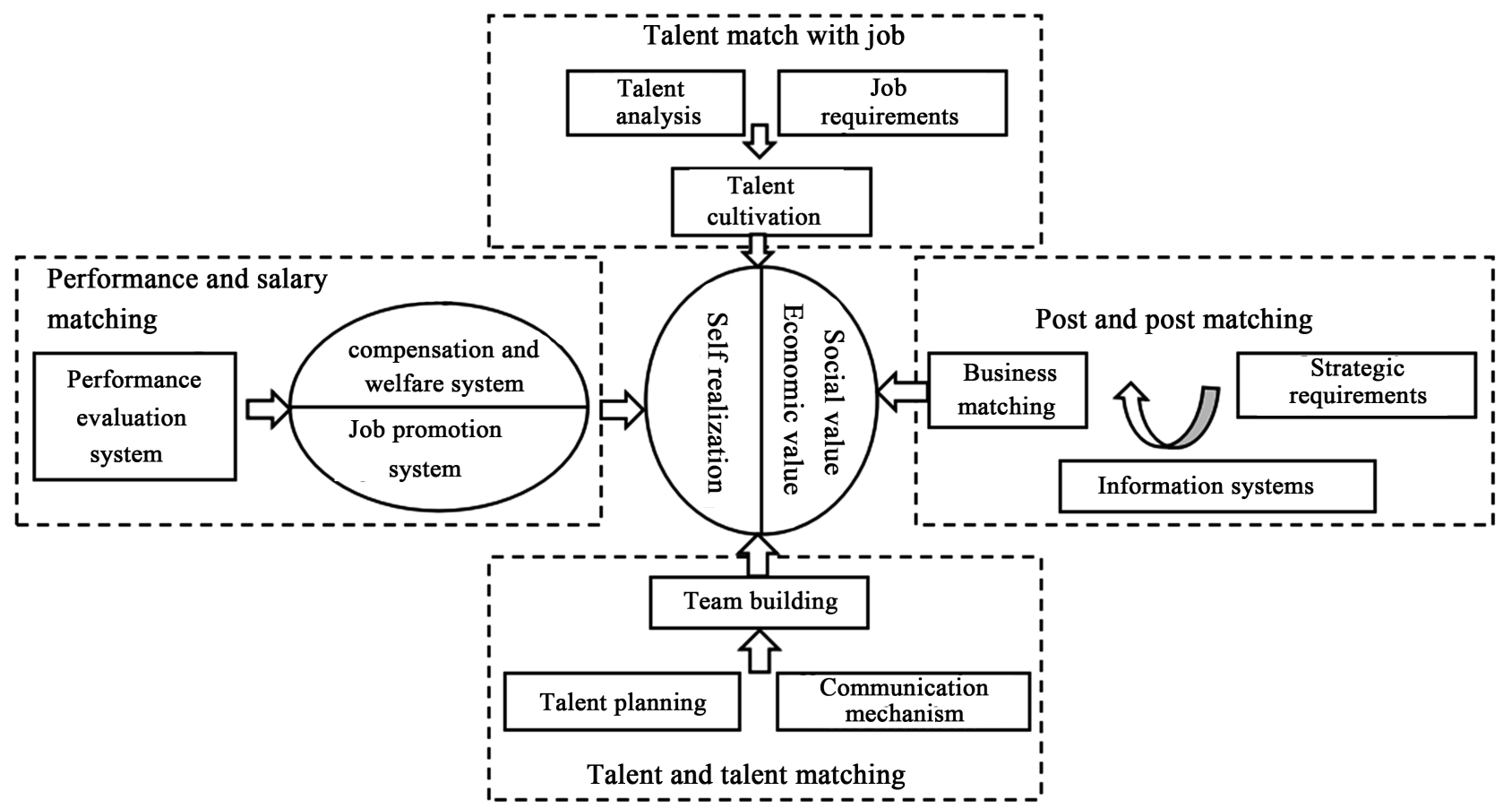

Figure 1. Human resources component map. Attached: This is derived from the author.

Table 5. Summary of main category and sub category.

\begin{tabular}{cl}
\hline Talent and talent matching & \multicolumn{1}{c}{ Communication mechanism, talent planning, team building } \\
\hline Talent match with job & Talent cultivation, talent analysis, job requirements \\
$\begin{array}{c}\text { Performance and } \\
\text { salary matching }\end{array}$ & $\begin{array}{l}\text { Performance evaluation system, compensation and } \\
\text { welfare system, job promotion system }\end{array}$ \\
Post and post matching & Business Matching, Strategic Requirements, Information Systems \\
Employee value & Self-realization \\
Corporation value & Economic value, social value
\end{tabular}

Attached: This is derived from the author.

extracted. Self-actualization is the ultimate pursuit of employees' work. What companies pursue is social value and economic value. Both are prerequisites for employees and corporate behavior. Human post matching is the foundation, performance and salary matching are tools, post matching is the matching of business requirements, people match is the match of project development, and four matches constitute human resource management.

\section{Discussion and Explanation}

\subsection{People Matching}

Talent analysis. Talent analysis mainly refers to the analysis of the explicit capabilities and potential of talents. Explicit ability analysis includes general skills and professional skills. Among them, common skills include office automation, document writing, and conference management. Professional skills are different 
according to different standards of the company's business sector; potential includes universal potential and identification, and general potential. Including the ability to perform communication, etc., identification refers to the sense of responsibility, logical thinking and so on.

Job requirements. The job requirements are a description of what the incumbent actually does, how to do it, and under what conditions of work, also known as job descriptions. It mainly includes the post mark, job summary, job responsibilities, working relationship, incumbent's authority and working conditions.

Talent cultivation. The cultivation of talents is based on job requirements and talent analysis. Based on job requirements, talents lack the ability or knowledge of which aspects, or need to strengthen or excavate which aspects of the skills, etc. and start talent cultivation, the purpose is to better to match job requirements and complete job assignments.

\subsection{Performance and Salary Matching}

Performance evaluation system. The performance evaluation mainly aims at the corresponding evaluation and feedback of the employee's performance in the job. For the easy-to-measure performance evaluation, it is measured by the periodicity of the corresponding indicators, such as the monthly qualification rate and annual output. For the performance that is difficult to measure digitally, the indirect indicators are used to measure the periodicity.

Remuneration and welfare system. The compensation and welfare system is to set the corresponding compensation grade and welfare package for different employee levels to choose from. It is the visualized harvest of the employees after they have paid for their work, and it is more reflected in the material level of benefits, which helps improve employee satisfaction and well-being. The enthusiasm of employees has a certain incentive.

Job promotion system. The promotion of positions is more reflected in the career development space and self-development of employees, and it is a demand that is higher than the material level.

\subsection{Post Matching}

Strategic needs. The strategic needs are the strategic plans that the company has made based on a series of factors such as the environment and the market to realize economic and social values.

Business match. The implementation of strategic planning is mainly reflected in the implementation of the business. The strategy involves many factors and covers a wide range of fields. Therefore, it is necessary to closely cooperate with each other to achieve precise matching.

Information system. The information system is the transmission link between strategic requirements and business matching. Strategic information is passed to the business department through the information system, and the 
business department combines based on the nature and requirements of the business to achieve strategic planning.

\subsection{People Matching}

Talent planning. Talent planning services for Gang Kong matching are the basis for fulfilling strategic requirements for business operations. Taking business needs as a starting point, we analyze the talents and capabilities that are needed to complete the business in order to carry out talent planning.

Communication mechanism. Different people have different backgrounds in life, diversified experience and education level, and have subjective initiative. For the same thing, there will be different views or opinions. In order to make everyone's opinions consistent and coordinated, we need to match the corresponding communication mechanism, reduce the useless work, improve work efficiency, and maximize the team effectiveness.

Team building. The team refers to the various combinations of personnel within the organization, such as between departments, between peers, between the lower and upper levels, and so on. In management, most managers tend to choose perfect talents. Such talents have most of the ability and can be qualified for various positions. Hiring such talents requires high costs. Therefore, in the match for all, we should use strategic principles as a guide and adopt complementary principles to form teams.

\section{Conclusions}

\subsection{Research Conclusions}

1) Human resources management consists of four basic elements: matching of post matching, performance-based salary matching, post matching, and matching of people. Among them, post matching is the basis; performance-based compensation matching plays an incentive role, and post matching and matching serve strategic needs. Everyone's matching is the essence of matching posts and is the essence of the realization of strategic requirements.

2) The ultimate orientation of human resource management activities is the realization of employees' self-worth and the realization of corporate value. Among them, the realization of the value of employees is the prerequisite for the realization of the value of the company. It is not an antagonistic relationship between employees and companies, but a win-win relationship. Under the support of the company, employees fulfill their job responsibilities and meet the material and spiritual needs. The company realizes the economic value and social value because of the value creation of the employees. The two complement each other.

3) The most critical part of the post matching is talent, not post. The establishment of the position is attached to the strategy of the company. The strategic positioning of the company is attached to the top management, that is, talents. Human resource management activities are carried out at the core of 
people, and incentive measures are tools.

4) The operation of human resource management activities comes from the synergy between various elements. Its essence is a series of commercial activities carried out under the guidance of strategic objectives, based on positions, and human-centered.

\subsection{Inadequate Research}

1) The case study method adopted in this paper has limitations. This paper adopts the single case study method to deeply analyze representative and typical case enterprises and explore the connotation of human resource management activities. However, the number of cases still has certain limitations. The universality of the research conclusions needs to be further verified.

2) The research method of this article is grounded theory. Although the coding process is kept as neutral as possible, and coding groups are established and memos are written to reduce the influence of the supervisory factors on the coding results, it is still difficult to completely avoid the influence of subjective factors in the process.

\subsection{Research Innovation}

1) Research Perspective: Based on the matching perspectives of people and posts, this article uses the grounded theory to deeply explore the connotation of human resource management in case studies, and enriches and develops the understanding of the connotation of human resources management in the academic community. Previous scholars believe that human resources management consists of six parts: human resources planning, recruitment and deployment, training and development, performance management, compensation and benefits management, and employee relationship management. This study extracts human resources management activities that consist of human post matching, performance compensation matching, post matching, and person matching.

2) Research methods: Using grounded theory qualitative research methods to carry out research, starting with the original data as the basis for coding, refining 15 subcategories and 4 main categories, with certain scientific and persuasive.

\section{Conflicts of Interest}

The author declares no conflicts of interest regarding the publication of this paper.

\section{References}

[1] Zhou, P.P. (2015) China's Undergraduate Students Reached 25,477,000 Last Year. http://scitech.people.com.cn/n/2015/0307/c1057-26654849.html

[2] Huang, N. (2014) Survey on the Current Situation of Human Resource Management in Small and Medium-Sized Enterprises in the Pearl River. Modern Industry, No. 2, 43.

[3] Tang, D.Z. and Zhang, Z.X. (2013) Human Post Dynamic Matching. Business 
Management, No. 9, 65-67.

[4] Luo, W.L. (2003) Individual-Post Dynamic Matching Model of Human Resource Allocation. Management Consulting, No. 5, 24-27.

[5] Huang, H.S. and Liu, F. (2000) Post Matching System Theory. Journal of Guangdong Institute of Public Administration, No. 12, 37-42.

[6] Wang, L.P. (2002) Basics of Matching Method for Non-Gang Jobs: Work Design. Human Resource Management Technology, No. 2, 45-47.

[7] Xu, R.R. (2012) A Discussion on the Post Matching Theory. Business Management, No. 9, 23-24.

[8] Jin, Y.H. and Wang, C.M. (2001) Research Progress and Significance of Human-Tissue Matching. Ergonomics of Human Engineering, No. 6, 36-40.

[9] Fei, X.D. (2008) Rooted in Theoretical Research Methodology: Elements, Research Procedures and Criteria. Public Administration Review, No. 3, 24.

[10] Bian, G.Y. (2009) Building Grounded Theory, Qualitative Research Guidelines. 